\title{
Desenvolvimento de bebida mista à base de suco de frutas tropicais e cereais utilizando a metodologia de superfície de resposta
}

\author{
R. A. ZAMBELLI ${ }^{1}$, S. C. P. MELO ${ }^{1}$, D. L. BRASIL' ${ }^{1}$, G. K. PINHEIRO ${ }^{1}$, L. I. F. PINTO, E. \\ R. PONTES ${ }^{1}$ e D. F. PONTES ${ }^{1}$. \\ ${ }^{1}$ Universidade Federal do Ceará, Departamento de Tecnologia de Alimentos. \\ E-mail para contato: Zambelli@alu.ufc.br
}

\begin{abstract}
RESUMO - O estudo teve o objetivo de desenvolver uma bebida mista à base de suco de caju e acerola, com aveia e linhaça e estudar os parâmetros de qualidade. Foi aplicado um delineamento composto central rotacional, com a aveia e linhaça sendo as variáveis independentes, incorporadas nos niveis de 0 a $10 \mathrm{~g}$, totalizando 11 ensaios, para verificar a influência no $\mathrm{pH}$, acidez, sólidos solúveis e nos parâmetros de cor ( $\mathrm{L}^{*}$, $\left.\mathrm{a}^{*}, \mathrm{~b}^{*}\right)$. A região ótima para o $\mathrm{pH}$ foi de valores superiores a 4,40 com adição de 7 a 10 $\mathrm{g}$ de linhaça, com quantidades superiores $5 \mathrm{~g}$ de aveia. A acidez variou de 0,207\% (E6) a $0,250 \%$ (E7). O teor de sólidos solúveis teve a região de otimização para valores superiores a $12,20^{\circ}$ Brix, com 3 a $7 \mathrm{~g}$ de linhaça e até $8 \mathrm{~g}$ de aveia. A luminosidade foi elevada pela adição superior a $8 \mathrm{~g}$ de aveia, para $8 \mathrm{~g}$ de linhaça este parâmetro foi reduzido. A cromaticidade $\mathrm{a}^{*}$ teve região ótima para valores superiores a $-1,60 \mathrm{e}$ superiores a 12,00 para a cromaticidade $b^{*}$, com maior influência da linhaça.
\end{abstract}

\section{INTRODUÇÃO}

A associação entre o consumo de frutas e legumes e uma diminuição no risco de doenças cardiovasculares e câncer é apoiado por evidências epidemiológicas consideráveis. O efeito benéfico deve-se a ação de compostos antioxidantes, que são capazes de neutralizar os radiciais livres e reduzir os danos oxidativos (Roesler et al., 2006). A atividade antioxidante de suco de acerola foi avaliada e, segundo Righetto et al. (2005), possui elevada capacidade antioxidante. Por sua vez, os produtos alimentícios do cajueiro (Anacardium occidentale L.) pode ser dividido em dois grupos: um de castanha de caju, a fruta real, e outra do pedúnculo do fruto a partir do qual, suco, doces e outros produtos podem ser produzidos. O suco de caju tem sabor agradável, sendo rico em vitamina C e em polifenóis (Damascendo et al., 2008).

A aveia branca (Avena sativa L.) é um cereal de excelente valor nutricional, fonte de fibras alimentares, rico em compostos antioxidantes, possuindo função nutritiva básica e propriedades fisiológicas benéficas, sendo considerado um grão integral, por apresentar, após seu processamento, o mesmo balanço de nutrientes encontrado na matéria-prima original (Gutcoski et al., 2009; Piovesana et al., 2013). A linhaça dourada (Linum usitatissimum L.) é uma das maiores fontes de ácidos graxos essenciais, possuindo vários compostos fenólicos com atividade antioxidante. Contém ácidos graxos ômega-3 (60\%) e ômega-6 (16\%), minreais, vitaminas, fibras e lignanas (Galvão et al., 2008; Colpo et al., 2006). 
O estudo tem como objetivo desenvolver, através do delineamento composto central rotacional, suco misto de acerola e caju incorporado com aveia e linhaça e avaliar o efeito sobre a qualidade do produto.

\section{METODOLOGIA}

\subsection{Delineamento Experimental}

Para o desenvolvimento das formulações de suco misto de caju e acerola foram utilizados polpas congeladas industrializadas. O suco foi formulado com $50 \%$ de cada fruto, com a adição de $20 \%$ de sacarose, com diluição em água potável de 1:1.

Na tabela 1 são apresentados as faixas de valores codificados e reais utilizados para os ensaios e na tabela 2 é apresentada a matriz do planejamento.

Tabela 1 - Variáveis e níveis do planejamento experimental completo $2^{2}$

\begin{tabular}{|c|c|c|c|c|c|}
\hline \multirow[b]{2}{*}{ Variáveis Independentes } & \multicolumn{5}{|c|}{ Níveis codificados e reais das variáveis independentes } \\
\hline & $-\alpha=-1,41$ & -1 & $\mathbf{0}$ & +1 & $+\alpha=+1,41$ \\
\hline & 0 & 2,5 & 5 & 7,5 & 10 \\
\hline Linhaça (g) & 0 & 2,5 & 5 & 7,5 & 10 \\
\hline
\end{tabular}

Para o desenvolvimento das formulações de suco misto incorporadas com diferentes quantidades de aveia e linhaça foi utilizado o Delineamento Composto Central Rotacional (DCCR). Foi aplicado um planejamento fatorial $2^{2}$ completo, totalizando 11 ensaios.

Tabela 2 - Matriz do delineamento experimental com valores codificados e reais

\begin{tabular}{ccccc}
\hline Ensaios & Aveia & Linhaça & Aveia $(\mathbf{g})$ & Linhaça $(\mathbf{g})$ \\
\hline $\mathbf{1}$ & -1 & -1 & 2,5 & 2,5 \\
$\mathbf{2}$ & +1 & -1 & 7,5 & 2,5 \\
$\mathbf{3}$ & -1 & +1 & 2,5 & 7,5 \\
$\mathbf{4}$ & +1 & +1 & 7,5 & 7,5 \\
$\mathbf{5}$ & $-1,41$ & 0 & 0,0 & 5,0 \\
$\mathbf{6}$ & $+1,41$ & 0 & 10,0 & 5,0 \\
$\mathbf{7}$ & 0 & $-1,41$ & 5,0 & 0,0 \\
$\mathbf{8}$ & 0 & $+1,41$ & 5,0 & 10,0 \\
$\mathbf{9}$ & 0 & 0 & 5,0 & 5,0 \\
$\mathbf{1 0}$ & 0 & 0 & 5,0 & 5,0 \\
$\mathbf{1 1}$ & 0 & 0 & 5,0 & 5,0 \\
\hline
\end{tabular}

\subsection{Avaliação da qualidade do suco misto}

pH: Alíquotas de $50 \mathrm{~mL}$ de suco misto foram colocados em béqueres de $100 \mathrm{~mL}$ para leitura direta em pHmetro (TEC-5 TECNAL), conforme metodologia do Instituto Adolfo Lutz (2005). 
Acidez: foram utilizadas $10 \mathrm{~mL}$ de suco misto, sendo diluídas em $100 \mathrm{~mL}$ de água destilada em erlenmeyer de $250 \mathrm{~mL}$, foram adicionadas de 2 a 4 gotas do indicativo fenolftaleína, as amostras foram tituladas com solução $\mathrm{NaOH} 0,1 \mathrm{~N}$ até o ponto de viragem, com três repetições e o resultado foi expresso em \% de acidez em solução molar, de acordo com o Instituto Adolfo Lutz (2005).

Sólidos solúveis totais (SST): determinação por refratometria, descrito pelo Instituto Adolfo Lutz (2005), utilizando refratômetro de bancada do tio Abbé.

Vitamina C: foi realizada por volumetria com utilização de iodo padronizado para oxidoredução, segundo Haida (2005) e cada $\mathrm{mL}$ de iodo gasto na titulação correspondente a $8,806 \mathrm{mg}$ de Vitamina C.

Análise de cor instrumental: determinada em colorímetro digital Minolta CR-300 (Osaka, Japão), com $8 \mathrm{~mm}$ de área de mensuração e geomeria d $/ 0^{\circ}$ no sistema CIELab, com leituras realizadas em ângulo de visão de $10^{\circ}$ e iluminante padrão D65. Os parâmetros medidos foram luminosidade $\left(\mathrm{L}^{*}\right)$ e as coordenadas de cromaticidade $\left(\mathrm{a}^{*} \mathrm{e} \mathrm{b}^{*}\right)$.

\subsection{Análise Estatística}

A avaliação dos resultados das variáveis independentes no desenvolvimento das formulações através do delineamento composto central rotacional foi realizada por superfície de resposta e suas respectivas curvas de contorno após a análise de variância (ANOVA) e regressão, foi realizado teste de médias ao nível de 5\% de significância. A análise foi realizada no programa STATISTICA 7.0.

\section{RESULTADOS E DISCUSSÃO}

A figura 1 apresenta a superfície de resposta e a curva de contorno da ação da aveia e linhaça sobre o $\mathrm{pH}$ do suco misto.
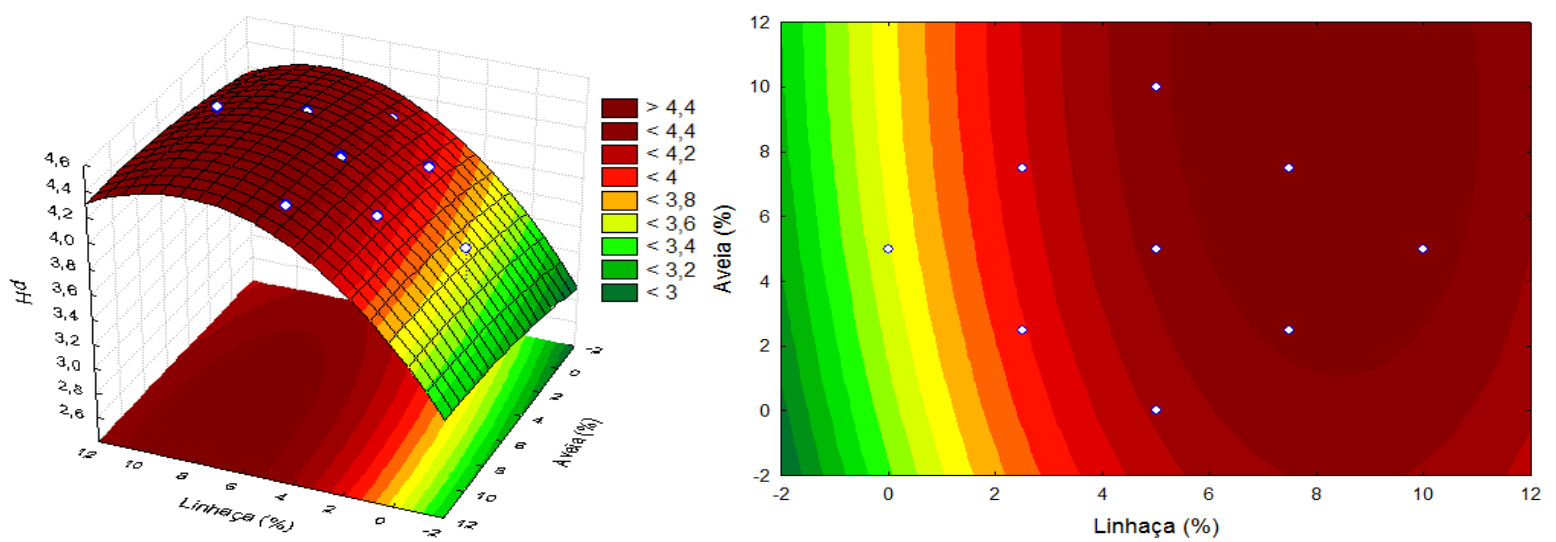

Figura 1 - Superfície de resposta e curva de contorno da ação da aveia e linhaça sobre o pH do suco misto

Verificou-se que a Aveia reduz o $\mathrm{pH}$ do suco misto de caju e acerola, sem a incorporação da linhaça, os valores ficaram na região de $\mathrm{pH}$ até 3,60. A linhaça elevou o pH para valores superiores a 4,40 sendo a região ótima, compreendendo nas adições de 7 a $11 \mathrm{~g}$ 
de linhaça e 3 a $12 \mathrm{~g}$ de linhaça. $\mathrm{O}$ pH obtido pelos ensaios variou de 3,49 (ensaio 5) a 4,51 (ensaio 6).

A figura 2 apresenta a superfície de resposta e curva de contorno da ação da aveia e linhaça sobre o sólidos solúveis totais (SST).
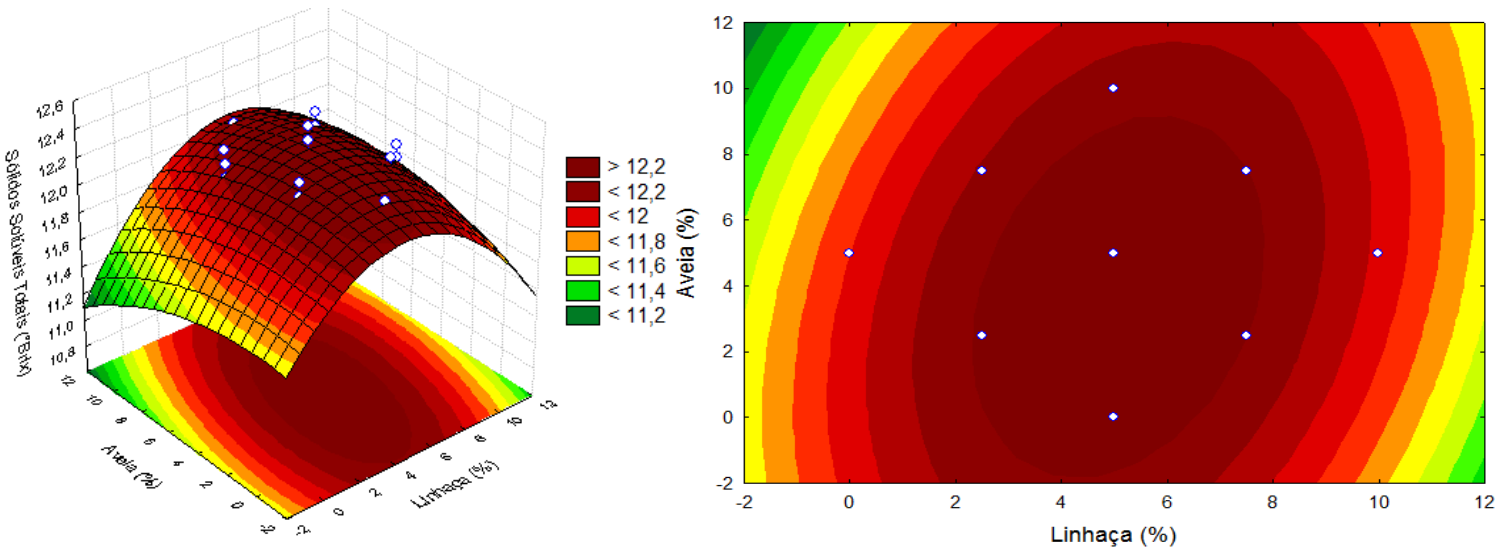

Figura 2 - Superfície de resposta, curva de contorno da ação da aveia e linhaça no teor de sólidos solúveis totais do suco misto

A zona de maximização compreendeu para valores superiores a $12,2{ }^{\circ}$ brix, com adição de linhaça entre 3 a $7 \mathrm{~g}$ e entre 0 a $8 \mathrm{~g}$ de aveia. Os valores obtidos pelos ensaios variaram de 11,83 (ensaio 5) a 12, 43 para o ensaio 9. Observou-se que a incorporação de quantidades superiores a 8 gde linhaça promovem a redução do sólidos solúveis totais.

Através da análise de variância não foi possível obter ajuste significativo para a obtenção das superfícies de resposta dos parâmetros de Acidez, Vitamina C e a análise instrumental de cor. A tabela 3 apresenta os valores obtidos para os parâmetros de qualidade do suco misto com a adição de aveia e linhaça.

Tabela 3 - Parâmetros de qualidade do suco misto com a adição de aveia e linhaça

\begin{tabular}{|c|c|c|c|c|c|}
\hline Ensaios $^{1}$ & $\begin{array}{c}\text { Aveia } \\
\text { (g) }\end{array}$ & Linhaça $(g)$ & Acidez (\%) & $\begin{array}{c}\text { Vitamina C } \\
(\mathrm{mg} / 100 \mathrm{~mL})\end{array}$ & $\begin{array}{c}\text { Sólidos } \\
\text { Solúveis Totais } \\
\left({ }^{\circ} \text { Brix }\right)\end{array}$ \\
\hline E01 & 2,5 & 2,5 & $0,248^{\mathrm{ab}} \pm 0,01$ & $125,06^{\mathrm{ef}} \pm 1,82$ & $12,30^{\mathrm{bc}} \pm 0,08$ \\
\hline E02 & 7,5 & 2,5 & $0,246^{\mathrm{ab}} \pm 0,02$ & $122,89^{\mathrm{bcf}} \pm 1,46$ & $12,20^{\mathrm{cde}} \pm 0,10$ \\
\hline E03 & 2,5 & 7,5 & $0,222^{\mathrm{ab}} \pm 0,01$ & $123,82^{\mathrm{bf}} \pm 0,51$ & $12,20^{\mathrm{cde}} \pm 0,09$ \\
\hline E04 & 7,5 & 7,5 & $0,252^{\mathrm{a}} \pm 0,01$ & $129,24^{\mathrm{e}} \pm 1,32$ & $12,28^{\mathrm{cde}} \pm 0,05$ \\
\hline E05 & 0,0 & 5,0 & $0,215^{\mathrm{ab}} \pm 0,02$ & $126,67^{\mathrm{ef}} \pm 1,02$ & $11,83^{\mathrm{a}} \pm 0,10$ \\
\hline E06 & 10,0 & 5,0 & $0,207^{\mathrm{b}} \pm 0,01$ & $115,58^{\mathrm{ad}} \pm 2,50$ & $12,00^{\mathrm{ad}} \pm 0,05$ \\
\hline E07 & 5,0 & 0,0 & $0,250^{\mathrm{ab}} \pm 0,01$ & $125,69^{\mathrm{ef}} \pm 3,14$ & $12,23^{\mathrm{cde}} \pm 0,03$ \\
\hline E08 & 5,0 & 10,0 & $0,247^{\mathrm{ab}} \pm 0,01$ & $118,60^{\mathrm{cd}} \pm 0,05$ & $12,13^{\mathrm{cd}} \pm 0,05$ \\
\hline E09 & 5,0 & 5,0 & $0,245^{\mathrm{ab}} \pm 0,02$ & $119,10^{\mathrm{bcd}} \pm 1,50$ & $12,43^{\mathrm{b}} \pm 0,04$ \\
\hline E10 & 5,0 & 5,0 & $0,246^{\mathrm{ab}} \pm 0,01$ & $112,96^{\mathrm{a}} \pm 1,53$ & $12,13^{\mathrm{cd}} \pm 0,03$ \\
\hline E11 & 5,0 & 5,0 & $0,236^{\mathrm{ab}} \pm 0,02$ & $127,36^{\mathrm{ef}} \pm 0,32$ & $12,23^{\mathrm{cde}} \pm 0,04$ \\
\hline
\end{tabular}

${ }^{1}$ Letras distintas em uma mesma coluna apresentaram diferenças significativas ao nível de $5 \%$ de significância $(\mathrm{p} \leq 0,05)$ 
A acidez do suco misto de caju e acerola incorporado com diferentes quantidades de aveia e linhaça variou de 0,207\%, para o ensaio 6, a 0,248\% (ensaio 1). Apresentaram diferenças significativas, ao nível de $5 \%$ de significância, apenas os ensaios 4 e 6 , os demais, não diferiram entre si. Os teores de vitamina $C$ variaram entre 112,96 (ensaio 10) a 125,69 (ensaio 7), não apresentaram diferenças significativas entre si os ensaios 1, 3 e 11. Verificouse que quando foi adicionado a maior quantidade de aveia no delineamento, foi obtido um valor inferior de vitamina $\mathrm{C}$ quando incorporado a quantidade máxima de linhaça. $\mathrm{O}$ teor de solidos solúveis totais variou entre 11,83 quando foi adicionado apenas $5 \mathrm{~g}$ de linhaça a 12,28 quando incorporado 7,5 g de aveia e linhaça, não apresentaram diferenças significativas os ensaios 2, 3, 4, 7 e 11; 8 e 10 .

Faraoni et al., (2012) estudaram o desenvolvimento de suco misto de manga, goiaba e acerola utilizando delineamento de misturas, verificaram que os valores de vitamina $\mathrm{C}$ variaram entre $32,00 \mathrm{mg} / 100 \mathrm{~mL}$ a $69,29 \mathrm{mg} / 100 \mathrm{~mL}$, quando incorporado o nível máximo de suco de acerola, valores inferiores aos obtidos neste estudo. Os valores de acidez obtidos foram da ordem de 0,19 a 0,25 g de ácido por $100 \mathrm{~mL}$ de suco, havendo similaridade com a acidez apresentada pelos sucos mistos de caju e acerola contendo aveia e linhaça. Morzelle et al., (2011) encontraram teor de sólidos solúveis superior, na ordem de 14 a 16, em néctar misto de maracujá e aratum.

Tabela 4 - Parâmetros de qualidade do suco misto com a adição de aveia e linhaça

\begin{tabular}{|c|c|c|c|c|c|}
\hline Ensaios $^{1}$ & $\begin{array}{c}\text { Aveia } \\
(\mathrm{g})\end{array}$ & $\begin{array}{c}\text { Linhaça } \\
\text { (g) }\end{array}$ & $\mathbf{L}^{*}$ & $\mathbf{a}^{*}$ & $\mathbf{b}^{*}$ \\
\hline E01 & 2,5 & 2,5 & $47,43^{\mathrm{c}} \pm 0,15$ & $-1,04^{\mathrm{a}} \pm 0,03$ & $12,65^{\mathrm{g}} \pm 0,10$ \\
\hline E02 & 7,5 & 2,5 & $48,77^{\mathrm{f}} \pm 0,16$ & $-1,77^{\mathrm{cde}} \pm 0,01$ & $12,99^{\mathrm{a}} \pm 0,01$ \\
\hline E03 & 2,5 & 7,5 & $49,11^{\mathrm{f}} \pm 0,13$ & $-1,60^{\mathrm{c}} \pm 0,02$ & $12,65^{\mathrm{g}} \pm 0,01$ \\
\hline E04 & 7,5 & 7,5 & $48,16^{\mathrm{b}} \pm 0,02$ & $-2,33^{\mathrm{b}} \pm 0,07$ & $11,90^{\mathrm{d}} \pm 0,03$ \\
\hline E05 & 0,0 & 5,0 & $44,47^{\mathrm{e}} \pm 0,25$ & $-2,24^{b} \pm 0,15$ & $10,66^{\mathrm{b}} \pm 0,09$ \\
\hline E06 & 10,0 & 5,0 & $46,49^{\mathrm{d}} \pm 0,21$ & $-2,34^{\mathrm{b}} \pm 0,19$ & $11,37^{\mathrm{e}} \pm 0,21$ \\
\hline E07 & 5,0 & 0,0 & $44,71^{\mathrm{e}} \pm 0,04$ & $-1,86^{\mathrm{de}} \pm 0,02$ & $11,06^{\mathrm{f}} \pm 0,06$ \\
\hline E08 & 5,0 & 10,0 & $47,73^{b c} \pm 0,33$ & $-1,80^{\mathrm{cde}} \pm 0,06$ & $11,69^{\mathrm{de}} \pm 0,03$ \\
\hline E09 & 5,0 & 5,0 & $48,76^{\mathrm{f}} \pm 0,12$ & $-1,66^{\mathrm{cd}} \pm 0,04$ & $12,64^{\mathrm{g}} \pm 0,03$ \\
\hline E10 & 5,0 & 5,0 & $46,08^{\mathrm{d}} \pm 0,06$ & $-1,75^{\mathrm{cde}} \pm 0,01$ & $11,63^{\mathrm{d}} \pm 0,07$ \\
\hline E11 & 5,0 & 5,0 & $45,37^{\mathrm{a}} \pm 0,04$ & $-1,97^{\mathrm{e}} \pm 0,08$ & $11,30^{\mathrm{ef}} \pm 0,09$ \\
\hline
\end{tabular}

A luminosidade do suco misto variou de 44,71 a 49,11; verificou-se que a adição de aveia promoveu maior escurecimento ao produto. Não houve diferenças significativas na luminosidade entre os ensaios 2 e 3 , onde as quantidades dos ingredientes foram alternadas e no ensaio 9 , onde foram adicionadas quantidades iguais. A cromaticidade $a^{*}$ ficou entre $-1,04$ a -2,34; não houve diferenças significativas entre os ensaios 2,8 e 3; 4, 5 e 6 , onde observouse que a variação das quantidades de aveia e linhaça não promoveu modificações significativas.

Comportamento semelhante foi apresentado pela cromaticidade $b^{*}$, situou-se na faixa de variação entre 10,66 para o ensaio 5 a 12,99 quando foi adicionado 7,5 g de aveia e 2,5 g de linhaça (ensaio 2), não houve diferença significativa entre os ensaios 1 e 9 , ou seja, 
dobrada as quantidades de aveia e linhaça incorporadas, não produziu efeito significativo na cromaticidade $b^{*}$.

Castro et al., (2014) estudaram os parâmetros colorimétricos de suco misto de abacaxi e seriguela, os valores de luminosidade variaram entre 26,86 a 28,45 , a cromaticidade a* entre 2,35 a $-2,83$ e a cromaticidade $b$ entre 5,18 a 6,85. Observou-se que os valores de luminosidade foram inferiores aos obtidos pelo suco misto de caju e acerola, valores próximos foram constatados para a cromaticidade $\mathrm{a}^{*}$ e houve divergências com os apresentados para a cromaticidade $\mathrm{b}^{*}$, o uso do suco de acerola, de coloração avermelhada, foi a causa destas diferenças, uma vez que o abacaxi e siriguela apresentam tonalidades próximas.

\section{CONCLUSÃO}

Verificou-se que a adição de aveia e linhaça em suco misto de caju e acerola promoveu o aumento da acidez, dos solidos solúveis totais e não foi observada influência significativa nos teores de vitamina $\mathrm{C}$. Com relação aos parâmetros colorimétricos, a aveia promoveu a redução da luminosidade e não foi constatado influência nas cromaticidades $a^{*} e^{2} b^{*}$. As regiões ótimas de incorporação foram para até $5 \mathrm{~g}$ de aveia e entre 7 a $10 \mathrm{~g}$ de linhaça.

\section{REFERENCIAS}

CASTRO, D. S.; NUNES, J. S.; SILVA, F. B.; OLIVEIRA, T. K. B.; SILVA, L. M. M. Desenvolvimento e avaliação físico-química de néctar misto de abacaxi (Ananas comosus) e Siriguela (Spondias purpurea). Rev. Ver. Agrotec. Des. Sust., v. 9, p. 06-09, 2014.

COLPO, E.; FRIEDRICH, L.; ROSA, C. S.; OLIVEIRA, V. R. Benefícios do uso da semente de linhaça. Nutr. Pauta., v. 14, p. 25-28, 2008.

DAMASCENO, L. F.; FERNANDES, F. A. N.; MAGALHÃES, M. M. A.; BRITO, E. S. Non-enzymatic browing in clarified cashew apple juice during thermal treatment: kinects and process control. Food Chem., v. 106, p. 172-179, 2008.

FARAONI, A. S.; RAMOS, A. M.; GUEDES, D. B.; OLIVEIRA, A. N.; LIMA, T. H. S. F.; SOUSA, P. H. M. Desenvolvimento de um suco misto de manga, goiaba e acerola utilizando delineamento de misturas. Cie. Rur., v. 28, p. 382-389, 2012.

GALVÃO, E. L.; SILVA, D. C. F.; SILVA, J. O.; MOREIRA, A. V. B.; SOUZA, E. M. B. D. Avaliação do potencial antioxidante e extração subcrítica do óleo de linhaça. Cie. Tecnol. Alim., v. 28, p. 551-557, 2008.

GUTKOSKI, L. C.; TEIXEIRA, D. M. F.; DURIGON, A.; GANZER, A. G.; BERTOLIN, T. E.; COLLA, L. M. Influência dos teores de aveia e gordura nas características tecnológicas e funcionais de bolo. Cie. Technol. Alim., v. 29, p. 254-261, 2009.

HAIDA, K. S. Apostila de aulas práticas de bioquímica. Unipar-Campus Cascavel, 2005. $32 \mathrm{p}$. 
INSTITUTO ADOLFO LUTZ. Normas analíticas do Instituto Adolfo Lutz. 3. ed. São Paulo: IMESP, 2005. v. 1. 533p.

MORZELlE, M. C.; SOUZA, E. C.; ASSUMPÇÃO, C. F.; BOAS, B. M. V. Desenvolvimento e avaliação sensorial de néctar misto de maracujá (Passiflora edulis Sims). Rev. Bras. Prod. Agroind., v. 13, p. 131-135, 2011.

PIOVESANA, A.; BUENO, M. M.; KLAIN, V. M. Elaboração e aceitabilidade de biscoitos enriquecidos com aveia e farinha de bagaço de uva. Braz. J. Food Technol., v. 16, p. 68-72, 2013.

RIGHETTO, A. M.; NETTO, F. M.; CARRARO, F. Chemical composition and antioxidant activity of juices from mature and immature acerola (Malphigia emarginata DC.). Food Sci. Technol. Inter., v. 11, p. 315-321, 2005.

ROESLER, R.; MALTA, L. G.; CARRASCO, L. C.; PASTORE, G. Evaluation of the antioxidant properties of Brazilian cerrado fruit Annoa crassifora (Araticum). J. Food Sci., v. 71, p. 102-107, 2006. 